\title{
Del legado a los sueños...
}

"Estoy convencido de que en este dia somos dueños de nuestro destino, que la tarea que se nos ha impuesto no es superior a nuestras fuerzas, que sus acometidas no están por encima de las que puedo soportar. Mientras tengamos fe en nuestra causa y en una indeclinable voluntad de vencer, la victoria estará a nuestro alcance"

Winston Churchill

Es para mi un honor estar al frente de la Unidad de Neumología de la Facultad de Medicina y del Hospital Universitario San Ignacio en este momento que cumple 35 años, en especial por ser yo el último residente de Neumología que fue seleccionado por el Doctor Darío Maldonado para iniciar el programa en 1991.

Sin lugar a dudas, durante estos 35 años han ocurrido gran cantidad de cambios en el entorno de la salud, la Facultad de Medicina, el Hospital, los pacientes, la investigación y los estudiantes, hecho que ha llevado a cambios en el funcionamiento de la Unidad para estar acorde con estas situaciones por nuestra real razón de ser: los pacientes y los estudiantes.

Como lo describió claramente la Doctora Mary Bermúdez, la Unidad de Neumología se inició hace 35 años, gracias a nuestro Maestro y Profesor el Doctor Darío Maldonado, quien durante los primeros 15 años fue su director; sus predecesores en los últimos 20 años han dirigido su rumbo de manera acertada, entre ellos menciono a los Doctores Iván Solarte, Mary Bermúdez, Jairo Roa, Jully Sánchez y Patricia Hidalgo, gracias a quienes puedo escribir que el legado del Doctor Maldonado y el de mis profesores (Mary, Iván, Jairo) y mis alumnos (Patricia y Jully) han dado muchos frutos en diferentes aspectos.

En tal sentido, se han formado 37 excelentes neumólogos, se ha desarrollado gran cantidad de información científica nueva y recopilada, se han formado muchos médicos, enfermeras jefes y auxiliares de enfermeria, fisioterapeutas, entre otros, y se ha brindado atención a número no despreciable de personas que padecen problemas respiratorios sencillos y complejos. Definitivamente va mi sincero agradecimiento a todos ellos por esta labor y por todos los logros que han cosechado al día de hoy.

De otra parte, quisiera escribir acerca del presente y, en mi humilde parecer, de los retos que nos esperan. En la actualidad la Unidad de Neumología está conformada por 33 personas: 11 neumólogos (10 de adultos y 1 pediátrico), 3 enfermeras jefes, 2 técnicos de función pulmonar, 5 técnicos de polisomnografía, 3 auxiliares de enfermería, 6 fisioterapeutas respiratorias, 2 secretarias y una auxiliar administrativa. Hoy podemos definir nuestra Unidad como un conjunto de seres humanos que, por distintos caminos y rutas hemos convergido, y nos encontramos trabajando juntos, organizados en una estructura relativamente determinada, quienes con el uso de recursos físicos, financieros y tecnológicos, creamos, producimos y prestamos servicios orientados al bienestar y la salud de las personas, la investigación y la educación médica y paramédica.

Esta unión de seres humanos es sin duda el logro más valioso, en especial si se tiene en cuenta que trabajarmos en forma conjunta y en equipo para servir a otras personas, sumado a la grandeza y capacidad de cada uno de nosotros, depende de la forma como cada quien desarrolla su proyecto de vida individual alineado a un proyecto colectivo. Para llegar al trabajo en equipo fue necesario compartir objetivos, tener directrices claras y generar mente colectiva.

Durante los últimos años la Unidad ha venido creciendo en su estructura y ha pasado de una unidad de neumólogos generales a neumólogos con formación especial en algunos aspectos. Todo ello se ha asociado al trabajo interdisciplinar para la creación de grupos de trabajo para enfermedades específicas a fin de consolidar grupos con alto conocimiento, brindar mejores desenlaces para los pacientes, unificar conceptos con base en la mejor evidencia posible, y, finalmente, llevar a cabo una actividad altamente eficiente, con una buena relación costo/ desenlace, que favorece tanto a los pacientes, como a la educación y al sistema de salud. 
Por el otro lado, ha sido necesario crear alianzas que favorecen una atención en salud integral, con otros niveles de atención. Esto ha llevado a la creación de otras sedes de la Unidad en niveles inferiores de atención en salud, para asi poder realizar actividades integradoras dentro de todos los niveles de atención, esto es básica, media y alta, sin desconocer que una parte importante de las actividades que realizan los neumólogos, se desempeñan en actividades de alta especialización, pero con un compromiso grande para integrar grupos de trabajo de enfermedades en niveles de atención inferior.

El reto de ser una Unidad con altas especificaciones en muchas de las actividades emprendidas, es mantener la unión e integración entre sus miembros, a través de la conversación y puesta a tono entre todos, sin lugar a dudas, ayudados por la integración en niveles de atención de menor complejidad, por la educación médica y por el trabajo en equipo. A lo anterior se asocia una administración que favorece este trabajo en equipo y que permite la discusión de las decisiones que implican cambios, siempre anteponiendo los beneficios grupales sobre los particulares.

Nos espera la consolidación de más grupos de trabajo interdisciplinar que puedan llegar a ser grupos de excelencia académica, de servicio y de investigación; y, así mismo, la conformación de un mayor número de alianzas para el trabajo desde los primeros niveles de atención hasta la más alta complejidad, que favorezcan la integralidad para los pacientes y la eficiencia en el manejo de recursos para nuestro sistema de salud.

"La vida, para mi, no es una vela que se apaga. Es más bien una espléndida antorcha que sostengo en mis manos durante un momento, y quiero que arda con la máxima claridad posible antes de entregársela a futuras generaciones."

George Bernard Shaw

Darío Londoño, MD., MSc. Internista, Neumólogo. Jefe de la Unidad de Neumología, Hospital Universitario San Ignacio.

Profesor Asociado. Facultad de Medicina, Pontificia Universidad Javeriana. Bogotá, Colombia. E-mail: dlondono@javeriana.edu.co 